\title{
Reversing Back to the Basic: Infection Control Strategies
}

\author{
Mohammad Miah, Syeda Nafisa, Tara Bartley, Sandeep Kaur, Ahmed Ashoub \\ Queen Elizabeth Hospital Birmingham, Birmingham, UK \\ Email: mohammad.miahl@nhs.net
}

How to cite this paper: Miah, M., Nafisa, S., Bartley, T., Kaur, S. and Ashoub, A. (2020) Reversing Back to the Basic: Infection Control Strategies. Open Access Library Journal, 7: e6197.

https://doi.org/10.4236/oalib.1106197

Received: February 28, 2020

Accepted: April 21, 2020

Published: April 24, 2020

Copyright $\odot 2020$ by author(s) and Open Access Library Inc.

This work is licensed under the Creative Commons Attribution International License (CC BY 4.0).

http://creativecommons.org/licenses/by/4.0/

\begin{abstract}
Healthcare-associated infections are estimated to cost the NHS approximately $£ 1$ billion a year. In addition to increased costs, each one of these infections means additional use of NHS resources, greater patient discomfort and a decrease in patient safety. In the wake of the growing burden of healthcareassociated infections (HCAIs), the increasing severity of illness and complexity of treatment, superimposed by multi-drug resistant (MDR) pathogen infections, healthcare practitioners (HCPs) are reversing back to the basics of infection preventions by simple measures like hand hygiene. However, studies on hand hygiene compliance among healthcare workers have repeatedly shown poor compliance with hand hygiene. Prospective observational data were collected over 2 weeks on the basic hand hygiene behaviour of the employees. Prospective observational data were collected over 2 weeks. Employees from different categories were observed in different occasions for 217 times. Only $37 \%$ of the consultants were bare bellow elbow while nursing staffs, ANPs and the domestics achieved $100 \%$ performance. While it was about the alcohol hand rub use, $37 \%$ of the consultants used hand rubs before and 33\% both before and after. The ANPs achieved the highest performance, $70 \%$ of them used alcohol hand rub before and after each patient contact. The healthcare practitioners need to brace themselves to inoculate the simple, basic and effective practice of hand hygiene in their daily patient care activities. From this study, it is evident that the standard was partially met.
\end{abstract}

\section{Subject Areas}

Clinical Trials, Gastroenterology \& Hepatology, Translational Medicine

\section{Keywords}

Infection Control, Hand Hygiene, Bare Bellow Elbow, Alcohol Hand Rub 


\section{Background}

The transfer of organisms between humans can occur directly via hands, or indirectly via an environmental source (e.g. clinical equipment, toys or sinks). It is universally acknowledged that the hands are the principal route by which cross-infection occurs and that hand hygiene is the single most important factor in the control of infection. Hand hygiene is now regarded as one of the most important element of infection control activities. In 2010, in England, infectious diseases accounted for $7 \%$ of all deaths, $4 \%$ of all potential years of life lost (to age 75 ) and were also the primary cause of admission for $8 \%$ of all hospital bed days, and they are responsible for a large proportion of sickness absence from work [1]. It is estimated that 300,000 patients a year in England acquire a healthcare-associated infection as a result of care within the NHS, a prevalence rate of $8.2 \%$ [2]. In 2007, methicillin-resistant Staphylococcus aureus (MRSA) bloodstream infections and Clostridium difficile infections were recorded as the underlying cause of or a contributory factor in, approximately 9000 deaths in hospital and primary care in England. Healthcare-associated infections are estimated to cost the NHS approximately $£ 1$ billion a year. In addition to increased costs, each one of these infections means additional use of NHS resources, greater patient discomfort and a decrease in patient safety. In the wake of the growing burden of healthcare-associated infections (HCAIs), the increasing severity of illness and complexity of treatment, superimposed by multi-drug resistant (MDR) pathogen infections, healthcare practitioners (HCPs) are reversing back to the basics of infection preventions by simple measures like hand hygiene. However, studies on hand hygiene compliance among healthcare workers have repeatedly shown poor compliance with hand hygiene. The hands of HCWs are commonly colonized with pathogens like methicillin resistant $S$. aureus (MRSA), vancomycin resistant Enterococcus (VRE), MDR-Gram Negative bacteria (GNBs), Candida spp. and Clostridium difficle, which can survive for as long as $150 \mathrm{~h}$. Proper hand hygiene is the single most important, simplest, and least expensive means of reducing the prevalence of HAIs and the spread of antimicrobial resistance.

\section{Method \& Sample}

Prospective observational data were collected over 2 weeks from $4^{\text {th }}$ December to $17^{\text {th }}$ December 2017. Standard was set by the local guideline and the following things were monitored for different levels of employees. If they were bare bellow the Elbow, if they had rings with stones or grooves or wrist watches, if they used Alcohol-based hand rub before and after each patient contact. Employees from different categories were observed on different occasions for 217 times.

\section{Results}

Within 2 weeks' time, people from different staff groups were observed on different occasions for 217 times. Consultants were observed total 27 times during 
their ward round. Simultaneously Registrars were observed 35 times, SHOs 31 times, ANPs (advanced nurse practitioners) 44 times, nurses 61 times, allied professionals 30 times and the domestics 33 times. Only $37 \%$ of the consultants were bare bellow elbow while nursing staff, ANPs and the domestics achieved $100 \%$ performance (Table 1 ). This is obviously because of their dress code. While it was about the alcohol hand rub use, $37 \%$ of the consultants used hand rubs before and 33\% both before and after. The ANPs achieved the highest performance, $70 \%$ of them used alcohol hand rub before and after each patient contact (Figure 1).

\section{Discussion}

Hand hygiene is now regarded as one of the most important element of infection control activities. In 2010, in England, infectious diseases accounted for 7\% of all deaths, $4 \%$ of all potential years of life lost (to age 75 ) and were also the primary cause of admission for $8 \%$ of all hospital bed days, and they are responsible for a large proportion of sickness absence from work. In most healthcare institutions,

Table 1. Showing the findings indifferent employees about the infection control strategies.

\begin{tabular}{cccccc}
\hline Employee group & $\begin{array}{c}\text { Bare Below } \\
\text { Elbow }\end{array}$ & $\begin{array}{c}\text { Jewllery/Wrist } \\
\text { watches }\end{array}$ & $\begin{array}{c}\text { Hand Rub } \\
\text { (Before) }\end{array}$ & $\begin{array}{c}\text { Hand Rub } \\
\text { (After) }\end{array}$ & $\begin{array}{c}\text { Total } \\
\text { Number }\end{array}$ \\
\hline Consultants & 10 & 9 & 10 & 9 & 27 \\
Registrars & 28 & 6 & 15 & 16 & 35 \\
SHOs & 19 & 6 & 15 & 12 & 31 \\
ANPs & 44 & 0 & 31 & 31 & 44 \\
Nurses & 61 & 4 & 37 & 37 & 61 \\
Allied Health Professionals & 21 & 12 & 10 & 8 & 30 \\
Domestics/House Keepers & 33 & 9 & 12 & 8 & 33 \\
\hline
\end{tabular}

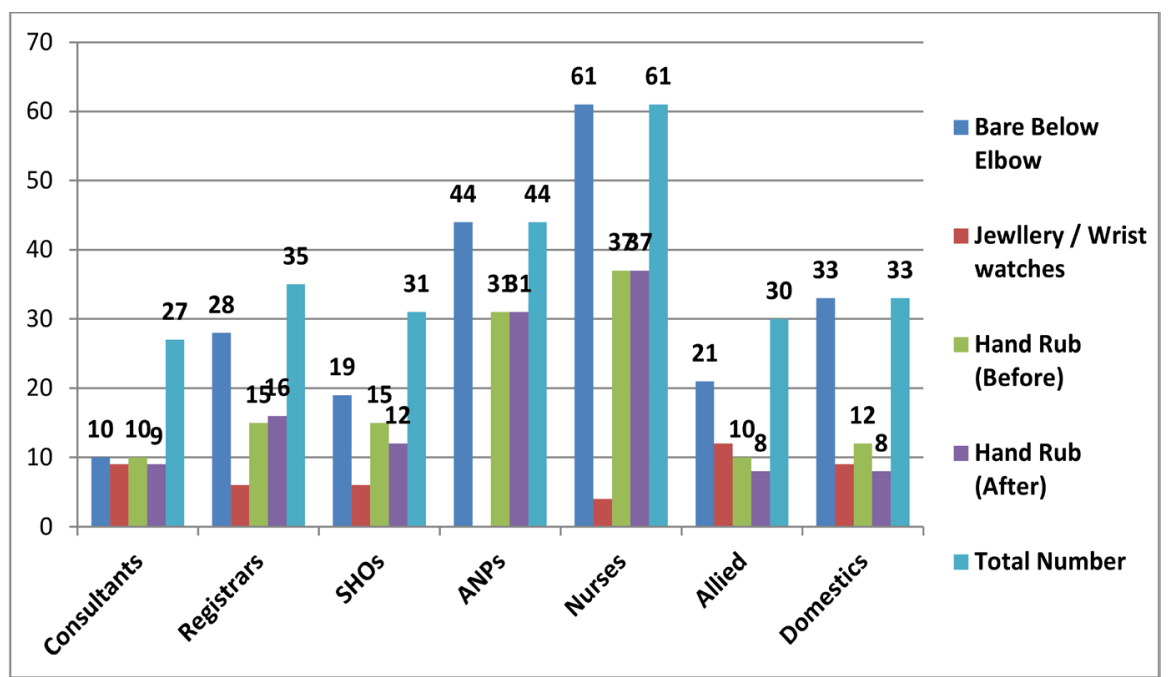

Figure 1. Showing performance of different level of employees in infection control strategies. 
Table 2. Factors influencing infection control strategies.

\begin{tabular}{|c|c|c|}
\hline Staff factor & Clinical factor & Environmental/Institutional factor \\
\hline Physician status & Working in ITU & $\begin{array}{l}\text { Believes that wearing gown and gloves take away } \\
\text { the needs of hand hygiene }\end{array}$ \\
\hline Male sex & $\begin{array}{l}\text { Weekdays Vs Weekends } \\
\text { working }\end{array}$ & $\begin{array}{l}\text { Inappropriate location of the hand hygiene } \\
\text { equipment }\end{array}$ \\
\hline Lack of Role model & Understaffing & $\begin{array}{l}\text { Belief of low risk of infection from inappropriate } \\
\text { hand hygiene }\end{array}$ \\
\hline Forgetfulness & Patient overcrowding & Lack of guidelines/Protocol \\
\hline Not thinking about & Insufficient time & Lack of institutional priority \\
\hline Lack of knowledge & Patient needs take priority & $\begin{array}{l}\text { Lack of administrative sanction of the } \\
\text { noncomplainers/rewarding compliers }\end{array}$ \\
\hline
\end{tabular}

adherence to recommended hand-washing practices remains unacceptably low, rarely exceeding 40 percent of situations in which hand hygiene is indicated [3] [4]. Hand hygiene reflects attitudes, behaviours and beliefs. Some of the observed/self-reported factors found to be affecting hand hygiene behaviours are enlisted in Table 2 [2] [5]-[10]. In our study, these factors also became more evident. The basic hand hygiene behaviours were observed in different level of staff over 2 weeks. Only $37 \%$ of the consultants were found bare bellow elbow while nursing staff, ANPs and the domestics achieved $100 \%$ performance. While it was about the alcohol hand rub use, $37 \%$ of the consultants used hand rubs before and 33\% both before and after. The ANPs achieved the highest performance, $70 \%$ of them used alcohol hand rub before and after each patient contact.

\section{Conclusion}

One of the reasons that microbes have survived in nature is probably their simplicity: a simple genomic framework with genetic encryption of basic survival strategies. To tackle these microbes, human beings will have to follow basic and simple protocols of infection prevention. From this study, it is evident that the standard was partially met. The healthcare practitioners need to brace themselves to inoculate the simple, basic and effective practice of hand hygiene in their daily patient care activities.

\section{Conflicts of Interest}

The authors declare no conflicts of interest regarding the publication of this paper.

\section{References}

[1] Annual Report of the Chief Medical Officer (2011) Volume Two Infections and the Rise of Antimicrobial Resistance.

[2] WHO Guidelines on Hand Hygiene in Health Care (2010) First Global Patient Safety Challenge. Clean Care is Safer Care. http://www.who.int/patientsafety/en/

[3] Trampuz, A. and Widmer, A.F. (2004) Hand Hygiene: A Frequently Missed Life- 
saving Opportunity during Patient Care. Mayo Clinic Proceedings, Vol. 79, 109-116. https://doi.org/10.4065/79.1.109

[4] Voss, A. and Widmer, A.F. (1997) No Time for Handwashing! Handwashing versus Alcoholic Rub: Can We Afford 100\% Compliance? Infection Control \& Hospital Epidemiology, 18, 205-208.

[5] Boyce, J.M. and Pittet, D. (2002) Guideline for Hand Hygiene in Health-Care Settings: Recommendations of the Healthcare Infection Control Practices Advisory Committee and the HICPAC/SHEA/APIC/IDSA Hand Hygiene Task Force. Infection Control \& Hospital Epidemiology, 23, S3-S40. https://doi.org/10.1086/503164

[6] Pittet, D., Mourouga, P. and Perneger, T.V. (1999) Compliance with Handwashing in a Teaching Hospital: Infection Control Program. Annals of Internal Medicine, 130, 126-130. https://doi.org/10.7326/0003-4819-130-2-199901190-00006

[7] Sax, H., Uckay, I., Richet, H., Aegranzi, B. and Pittet, D. (2007) Determinants of Good Adherence to Hand Hygiene among Healthcare Workers Who Have Extensive Exposure to Hand Hygiene Campaigns. Infection Control \& Hospital Epidemiology, 28, 1267-1274. https://doi.org/10.1086/521663

[8] Erasmus, V., Brouwer, W., van Beeck, E.F., Oenema, A., Daha, T. and Richardus, J.H. (2009) A Qualitative Exploration of Reasons for Poor Hand Hygiene among Hospital Workers: Lack of Positive Role Models and of Convincing Evidence That Hand Hygiene Prevents Cross-Infection. Infection Control \& Hospital Epidemiology, 30, 415-419. https://doi.org/10.1086/596773

[9] Schneider, J., Moromisato, D., Zemetra, B., Rizziwagner, L., Rivero, N. and Mason, W. (2009) Hand Hygiene Adherence Is Influenced by the Behavior of Role Models. Pediatric Critical Care Medicine, 10, 1-5. https://doi.org/10.1097/PCC.0b013e3181a32f16

[10] Pittet, D. (2001) Improving Adherence to Hand Hygiene Practice: A Multidisciplinary Approach. Emerging Infectious Diseases, 7, 234-240. 